\title{
1 Biomineralisation during operculum regeneration in the polychaete Spirobranchus
}

2 lamarcki

4 Réka Szabó ${ }^{1}$, Angus C. Calder ${ }^{2}$ and David E.K. Ferrier ${ }^{1}$

6 1. The Scottish Oceans Institute, Gatty Marine Laboratory, University of St Andrews, East

7 Sands, St Andrews, Fife, KY16 8LB. UK.

8 2. The School of Geography and Geosciences, Department of Earth and Environmental

9 Sciences, Irvine Building, University of St Andrews, Fife, KY16 9AL. UK.

e-mails: RS= rs386@st-andrews.ac.uk, ACC= acc@st-andrews.ac.uk, DEKF= dekf@st-

andrews.ac.uk

Keywords: calcification, serpulid, magnesium calcite, aragonite, X-ray diffractometry 
Formation of calcified biominerals is widespread in marine animals and is often associated with important elements of their biology, such as support and protection. Serpulid polychaetes are relatively understudied examples of biomineralisation despite their prominence in many marine ecosystems. An investigation of calcification in the regenerating opercular plate of the serpulid polychaete Spirobranchus (formerly Pomatoceros) lamarcki was performed using optical microscopy, calcein labelling and powder diffraction analysis. Worms were collected between January 2012 and June 2013 from East Sands beach, St Andrews, Scotland $\left(56.33^{\circ} \mathrm{N}, 2.78^{\circ} \mathrm{W}\right)$. The earliest visible signs of calcification were birefringent grains. Later-stage regenerates displayed a complex mixture of calcified structures including grains, round, smooth tiles, and larger tiles with a rugged appearance. The plate matures by the growth and eventual merging of tiles into a contiguous crust. Calcein pulse-chase experiments showed the progression of calcification from the centre towards the edge of the plate, and powder diffraction analysis of three regenerative stages revealed a major shift in mineralogy from a predominantly calcitic to a predominantly aragonitic composition. The mechanisms underlying the shift are currently unknown. These are the first mineralogical data comparing different developmental stages in a serpulid operculum, and contribute to the understanding of biomineralisation in this group. 
Organisms with mineralised hard parts are cornerstones of many marine ecosystems.

Biomineralisation occurs in phylogenetically diverse organisms and fulfils a wide variety of functions from skeletal support through defence to feeding. By far the most common minerals utilised by organisms are the various polymorphs of calcium carbonate, which makes many ecosystems vulnerable to on-going changes in ocean chemistry. 1989; Knoll 2003). Calcifying animals include such prominent members of marine Ecdysozoa, and molluscs, bryozoans, brachiopods and tube-dwelling annelids in the Lophotrochozoa. Among lophotrochozoans, molluscs are the best-studied calcifiers by far, with extensive research on shell structure, mineralogy, development and organic constituents (for reviews see Lowenstam and Weiner 1989; Addadi et al. 2006; Marin et al. 2007; 2012). However, calcifying annelids also play important roles in marine ecosystems. In prolific reef builders (Bosence 1973; Fornós et al. 1997; Smith et al. 2005; reviewed by Smith et al. 2013). Serpulids are an ideal group in which to study calcification for several reasons. They are ecologically important and affected by changing ocean chemistry (Ries et al. 2009; Ries 
61 serpulids probably made exclusively aragonitic tubes (Vinn et al. 2008a), the composition of

62

the tubes in terms of $\mathrm{CaCO}_{3}$ polymorphs is highly variable among living species (Vinn et al. 2008b; Smith et al. 2013), and tube ultrastructures range from the very simple to complex, multi-layered constructions indicative of a highly regulated mineralisation process (Vinn 2013, Vinn et al. 2008b, c; Vinn et al. 2009; Tanur et al. 2010). Furthermore, some serpulid lineages also possess a second kind of hard part in the form of a calcified operculum, an anterior appendage the worms use to plug their tubes. The operculum differs from the tube in its function, in the site of mineralisation, and, in the few cases where comparisons have been made, in mineralogy and/or ultrastructure (Bubel et al. 1983; Vinn and ten Hove 2011; Smith et al. 2013). Also, opercula are highly regenerative, making them amenable to developmental studies of calcification. Thus, serpulids offer a diverse array of biomineralisaton systems and a wealth of possibilities for the study of the evolution, development and ecological ramifications of biological calcification.

The serpulid Spirobranchus lamarcki is an intertidal species common around the British Isles. It has a prominent operculum with a calcified end plate (Fig. 1). The operculum of S. lamarcki is a cup-shaped structure situated at the end of a stout peduncle. Peduncle and cup together comprise the opercular filament. The cup has a flat or concave distal end plate with a central spine. The plate and spine are lightly calcified. The operculum can be autotomised or amputated at a predetermined point halfway along the peduncle (the easy break point, Fig. 1C), after which it rapidly regenerates (Bubel et al. 1980; 1985; Szabó and Ferrier 2014). Previous studies of calcification in S. lamarcki were mainly carried out by Bubel and co-workers, who determined the mineralogy of the tube and the mature opercular plate (Bubel et al. 1983), examined the ultrastructure of the opercular plate and 
its organic matrix (Bubel 1983; Bubel et al. 1983) and described histological and ultrastructural aspects of opercular regeneration (Bubel et al. 1980; 1985). According to Bubel (1983), the mature opercular plate consists of two structurally distinct calcified layers sandwiched between the opercular plate epithelium and an uncalcified organic layer. The outer calcified layer consists of an ordered array of prismatic crystals, while the inner layer is calcified with thin, needle-like crystals. Bubel (1983) observed that the mineral and the organic components of both layers appear to align well, indicating an important role for the organic matrix in structuring the calcified plate. The epithelial cells of the opercular plate extend microvilli into the calcified layers, and contain vesicles with what appear to be prism- or needle-like crystals inside. Bubel et al. (1983) determined the composition of the opercular plate as aragonitic.

Opercular regeneration after amputation at the easy break point begins with the formation of a swelling around the middle of the stump. The distal end of the stump gives rise to the cup within 2-3d, and calcification of the regenerating plate and spine is almost always apparent by day 3 (Szabó and Ferrier 2014). Bubel et al. (1985) dealt with the calcification of the plate during regeneration to some extent, noting needle-like calcification throughout using optical microscopy, calcein labelling and X-ray diffractometry (XRD). Microscopic

the plate at mid-regeneration, and the appearance of the prismatic layer in late regenerates. They provided X-ray diffraction data for late regenerates, again observing an aragonitic composition, but did not address the mineralogy of earlier stages.

Here, we investigate the development of the calcified plate during regeneration observations were used to document the general morphology of calcified plate elements 
throughout regeneration, an aspect of plate calcification that is poorly imaged and difficult to interpret in Bubel's work. We employed in vivo calcein labelling to trace the fate of calcareous deposits formed at various regenerative stages. In addition, we obtained new XRD data from early and mid-regeneration stages not represented in previous work.

\section{Materials and Methods}

\section{Spirobranchus lamarcki}

Rocks with adult Spirobranchus lamarcki living on them were collected from the rock pools at East Sands beach, St Andrews, Scotland between January 2012 and June 2013. Collected rocks were kept at ambient temperature in the seawater aquarium facilities of the Scottish Oceans Institute, Gatty Marine Laboratory, University of St Andrews, until needed.

Experimental worms were removed from their tubes by breaking the posterior end of the tube, widening this hole and then pushing the worm backwards out of the posterior tube hole with blunt forceps. Detubed worms were placed in 9-cm plastic Petri dishes containing 25-30 ml of filtered seawater (FSW; salinity 34) and kept in the dark in an air-conditioned room between $15-18^{\circ} \mathrm{C}$. Every few days the FSW was replaced with fresh. The worms were not fed. For regeneration experiments, opercular amputations were carried out with a scalpel at the easy break point (Fig. 1C). Amputated worms were then maintained as before.

Development of the calcified plate

Regenerating opercula of various stages were initially photographed with a Nikon Coolpix 4500 digital camera mounted on a dissecting microscope. To obtain more detail without disrupting unstable mineral phases, some regenerates were amputated, mounted in clean 
FSW and imaged immediately using a Leica microscope equipped with differential interference contrast (DIC) optics. Imaging of plate calcification was done with a QImaging Retiga 2000R camera and ImagePro Insight ${ }^{\circledR}$ version 8 . Figures for display were assembled and annotated in the GIMP 2.8 .

\section{Calcein labelling}

To track the fate of the calcified plate throughout regeneration, we used the fluorescent calcium-binding dye calcein. Live worms were soaked in FSW containing $100 \mu \mathrm{g} \mathrm{ml}^{-1}$ calcein for 24-h periods during opercular regeneration. Excess dye was then removed with five changes of FSW, and the worms were allowed to continue regeneration until $14 \mathrm{~d}$ postoperation (dpo). At that time, the regenerated opercula were removed and fixed in $4 \%$ paraformaldehyde (PFA) in phosphate buffered saline (PBS) for $30 \mathrm{~min}$ at room temperature. After fixation, the specimens were washed three times with PBS, dehydrated through an ethanol series, and finally cleared in $60 \%$ glycerol. For imaging of opercular plates, the distal portion of the operculum was gently sliced off with a razorblade to allow mounting with the plate lying flat. Calcein-labelled specimens were imaged with the same microscope and software as described above.

Opercular plate mineralogy

To test whether the composition of the calcified plate material changes during regeneration, opercula of three stages were collected for powder X-ray diffraction (XRD) analysis. We used pooled samples of early calcifying ( $2-3 \mathrm{dpo}, n=220$ ), strongly calcifying mid-regeneration (6 dpo, $n=98$ ) and non-regenerating (mature, $n=79$ ) opercula. Opercula were removed with a scalpel and fixed in absolute ethanol. Further sample processing and analysis was carried 
out in the Facility for Earth and Environmental Analysis (FEEA), School of Geography and

152 Geosciences, University of St Andrews. Specimens were air dried, stripped of organic matter in a plasma asher, powdered and analysed with a Siemens D500 X-ray diffractometer using cobalt $\mathrm{K} \alpha$ radiation. Data were recorded for $5^{\circ} \leq 2 \theta \leq 70^{\circ}$ in steps of $0.02^{\circ}$. Step times were $3 \mathrm{~s}$ for the mature, $5 \mathrm{~s}$ for the $6 \mathrm{dpo}$ and $10 \mathrm{~s}$ for the $2-3 \mathrm{dpo}$ sample. Semi-quantitative estimates of aragonite and calcite content were derived with Siroquant software, and the magnesium content (\% by weight) of the calcite phase was estimated based on Chave's (1952) work. Diffractograms for display were generated with R 2.14 (R Development Core Team 2012) and annotated in the GIMP 2.8.

\section{Results}

The Spirobranchus lamarcki opercular filament regenerates rapidly, regaining all of its major morphological features by 4-6 dpo (Bubel et al. 1980; 1985; Szabó and Ferrier 2014), after which regeneration is completed by further growth and the development of pigmentation. The cup-shaped operculum and its distal plate begin to form by 2-3 dpo, and the first visible calcification appears soon after plate development starts (Fig. 1D). Initially, calcification is apparent in the form of fine grains and round "tiles" around the base of the opercular spine. These tiles increase in number, grow and eventually contact one another to give the entire plate a "tiled" appearance (Fig. 1E). As the plate matures, the boundaries between tiles become less distinct (Fig. 1F).

DIC imaging at higher magnification revealed several types of calcified structure in regenerating plates. All of the following structures displayed interference colours 
characteristic of birefringent objects. 1. Elongated grains. The smallest discernible calcified structures have a smooth, rounded, often elongated appearance (Fig. 2A). Grains are on the order of a few microns, although they vary considerably in size (Fig. 2A and inset). Such grains are found on early regenerates that have just started calcifying, as well as surrounding tiles or at the edge of the calcified region in more mature opercula (Fig. 2B, C, opercula (Fig. 1D, Fig. 2A). These are relatively smooth in appearance and were often seen merging (Fig. 2B). In more mature opercula, tiles increase in number and size. Grains were often seen in close association with tiles, although it can be difficult to discern whether they occur on top of, under, or within the tile (Fig. 2A, B). Sometimes, simple tiles appeared to contain a grain at the centre (Fig. 2B, small tile in Fig. 2C). 3. Large, irregular tiles with growth lines (Fig. 2E-F) or a fan-like appearance (Fig. 2D), occur on older regenerating plates. Fan-like structures are particularly common near the edge of the calcified plate and often display fine radial lines (Fig. 2D). 4. Contiguous plate with a rugged, complex appearance. In most older regenerates, the central area of the plate is entirely calcified with no large uncalcified gaps. Unlike newly formed tiles in young regenerates, the plate of older regenerates does not look smooth with DIC optics. Rather, it has a complex, granular appearance with uneven boundaries of larger tiles discernible (Fig. 2G). Tiles with visible growth lines lack this granularity, but they can appear within more rugged plate regions (Fig. $2 \mathrm{E}-\mathrm{F})$.

Calcein labelling tracks the formation of these structures. In early-labelled specimens given a pulse of calcein at 2-3 dpo and then allowed to regenerate until $14 \mathrm{dpo}$, fluorescence was limited to the central region of the plate and/or the base of the spine, and corresponded to 
grains and small tiles (Fig. 3A, E). Pulses between 2-6 dpo generally resulted in compact, round regions or discrete ring shapes being labelled within the larger tiles forming the 14 dpo plate (Fig. 3B, F). In later pulses, grains were rarer, ring-like fluorescence was closer to the tile edge and less regular, while fainter fluorescence was seen across the surface of large tiles (Fig. 3C-D and G-H). As seen in DIC images (Fig. 2), the outer edge of the labelled area resembles earlier stages in that it contains smaller, more disjointed tiles and more grains

(Fig. 3B, F in particular). The centre of the plate and the spine always exhibit some staining regardless of the time of the pulse, but early pulses never produce fluorescence near the plate edge.

XRD results indicate major changes in mineral composition as the plate matures (Fig. 4).

Crystalline calcium carbonate could be detected at all stages (2-3 dpo, $6 \mathrm{dpo}$ and mature), although the small amount of mineral in young regenerates rendered the signal weak compared to later stages (compare Fig. 4A to Fig. 4B and C). Mature (unoperated) opercula are almost entirely aragonitic, but contrary to Bubel et al.'s (1983) report, small amounts of high- and low-Mg calcite were detected (Fig. 4C-D). In contrast, early calcifying regenerates contained mostly high- $\mathrm{Mg}$ calcite (cca. $12-16 \% \mathrm{MgCO}_{3}$ ), with aragonite in the minority and pure calcite undetectable (Fig. 4A, D). At mid-regeneration (6 dpo), plate mineral composition was intermediate between early and mature opercula (Fig. 4B, D). In diffractograms of mature plates, a small quartz peak was also discernible (Fig. 4A; see Discussion). 
We have studied calcification in regenerating opercula of the serpulid Spirobranchus

lamarcki. This species produces a multitude of calcified structures, including a mostly calcitic tube (Bubel et al. 1983), posterior abdominal calcifications of unknown mineralogy (pers. obs.; Thomas 1940; Hedley 1958) and a largely aragonitic opercular plate (Bubel et al. 1983; 1985; this study).

Like most examples of biological mineralisation, the opercular plate forms in a protected space, in this case between the plate epidermis and the cuticle. The first easily visible signs of calcification are areas covered in micrometre-scale grains, and larger, round tiles that are conspicuous even under a dissecting microscope. DIC imaging of these structures suggests that they are crystalline: even the smallest observable grains display interference colours characteristic of birefringent materials (Fig. 2A). The larger grains are elongated, rounded and shaped much like rice grains. Their orientations seem to be random, and they appear to occur in multiple tiers through the thickness of the plate (Fig. 2A). Importantly, they are often seen in association with tiles, and sometimes appear to be inside tiles (Fig. 2B).

The relationship between grains and tiles is not entirely clear from our observations. Grains certainly seem to contribute to tile growth, judging from their occurrence in/on and around expanding tiles (Fig. 2B-C, Fig. 3F). Calcein labelling revealed that unstained grains can obscure parts of tiles (Fig. 3F), which means they must be situated on top of the labelled region, although this could happen either with younger grains formed on top of a tile or with older grains that the tile grew under. Older regions of the plate can be very granular 
not modified to align with one another in any way. Smoother structures in older plate regions can appear half-buried in this granular material (Fig. 2E-F).

However, many tiles and other larger structures appear remarkably smooth (e.g. the

"fans" of the type seen in Fig. 2D), which indicates that they may either incorporate grain material but completely remodel its structure, or grow in a grain-independent manner.

Perhaps some of the otherwise smooth tiles with grains apparently inside them exemplify a stage in the former. Bubel's (1983) electron microscopic observations of the mature opercular plate recorded two structurally different calcified layers with aragonite crystals of different shapes and orientations. It would be interesting to know how these ultrastructural layers relate to the larger-scale structures we have observed with light microscopy.

calcification expands outward from the spine as the plate grows. In general, both in DIC and fluorescence images, the interior of the plate is clearly older than the edges. Tiles cease lateral growth when they encounter other tiles, but continue growing in the directions not impeded by the contact (Fig. 3F). The placement of tile "cores" appears to be random; while some early-labelled areas are in the middle of their respective tiles, others are much closer to one edge (Fig. 3E). Thus, if some sort of signalling system is involved in the development and differentiation of distinct cells with tile-producing capabilities, the system is not operating to produce a regular, evenly spaced pattern across the plate epidermis. Alternatively, if all plate epidermal cells are involved in deposition of calcified material, then they do so with highly variable rates and activities within the broader pattern of deposition starting at the base of the spine and progressing outwards. 
study reported only aragonite (Bubel et al. 1983), the opercular plates of S. lamarcki clearly contain more than one polymorph of calcium carbonate, and aragonite only becomes the dominant form later in regeneration. Second, the composition of opercular plate mineral changes radically during the course of regeneration. To our knowledge, this is the first developmental study of opercular plate mineralogy in any serpulid, making this result especially valuable. Third, consistent with the picture revealed by DIC microscopy, early calcification appears largely crystalline. In the spicules of the tunicate Pyura pachydermatina and the calcareous sponge Clathrina sp., amorphous calcium carbonate is the dominant phase and is apparent in powder diffractograms as a broad bump in the region where peaks for crystalline calcite would be (Aizenberg et al. 1996). While background is generally high in our early sample, a comparable bump is not evident in Fig. 4A.

Regarding the composition of the mature plate, contamination from other organisms or even non-biological sources must be considered. Our results from mature opercula contain a peak for quartz, which is most likely derived from environmental sand. To our knowledge, quartz (crystalline silica) formation by a living organism has never been reported, although hard parts made of amorphous silica are found in numerous taxa including sponges, diatoms and land plants (Lowenstam and Weiner 1989; Knoll 2003). With regards to the detection of low-Mg calcite, mature opercula are also associated with a wide range of commensal organisms; although every effort was made to remove such organisms,

282 it is impossible to completely exclude them from wild-collected opercula. Few reports exist on the magnesium content of calcite in serpulid opercula, but where such measurements have been made (reviewed by Smith et al. 2013), the calcitic components of both tubes and 
opercula usually incorporate a medium to high percentage of magnesium carbonate.

Therefore, the sudden appearance of low-Mg calcite in mature opercula should be treated with caution until it is confirmed by further research. investigation. Such changes are common in organisms that use more than one mineral phase in their hard parts. For example, some molluscs have calcitic components in their adult shells, which are deposited after the formation of the aragonitic larval shell (e.g. Medaković et al. 1997), and the radular teeth of chitons deposit several distinct mineral phases at different developmental times (Kirschvink and Lowenstam 1979). In bryozoans whose skeletons contain both aragonite and calcite, the presence of aragonite in particular skeletal elements can vary by zooid age (Taylor et al. 2008). aragonite. While amorphous precursors in biomineralisation have been a popular area for research, transformations of one crystalline polymorph into another are discussed less often. Lowenstam and Weiner (1989) review a handful of examples, including vaterite to aragonite transformations in snails and the replacement of octacalcium phosphate with dahllite in vertebrates. More recently, Taylor et al.'s (2008) investigation of bimineralic bryozoan skeletons found that the growing edges of the otherwise calcitic basal walls of Pentapora foliacea skeletons are made of aragonite, suggestive of a subsequent transformation into the calcite that makes up older parts of the wall. However, the opposite transformation is thermodynamically unfavourable and has only been reported from in vitro systems thus far (Cheng et al. 2008; Huang et al. 2012). In S. lamarcki, a certain amount of recrystallisation probably happens during plate development as randomly oriented grains 
are incorporated into smooth tiles, but we do not currently know how these two kinds of structure compare in terms of composition. A clear avenue for future research is the application of high-resolution methods such as Raman spectroscopy, which could provide information about the spatial distribution of different polymorphs in relation to the visible structures.

Spectroscopic methods would also help us elucidate whether the absence of amorphous precursors is real or due to the limitations of our methods. Amorphous or poorly crystalline precursors are increasingly recognised as a common and important feature of diverse biomineralisation systems (Addadi et al. 2003) including the apatite-based tooth enamel of vertebrates (Beniash et al. 2009), the aragonitic larval shells of molluscs (Weiss et al. 2002), the calcitic larval spicules of sea urchins (Beniash et al. 1997), and the bimineralic unstable, and as a transient precursor phase it may not be present in large quantities. Therefore, although we observed birefringence even in our fresh, unfixed specimens, and all of our XRD samples showed distinct calcite and aragonite peaks, our results cannot be used to definitively exclude the presence of ACC in S. lamarcki. that ACC, if present, is replaced by crystalline mineral before deposition into the plate matrix. Nonetheless, "amorphous" biominerals do in fact display a short-range order reminiscent of their crystalline counterparts (Addadi et al. 2003; Cartwright et al. 2012), and Beniash et al. (2009) observed that the amorphous phase in immature mouse enamel already assumes the form of the mature crystals. Thus, the appearance of crystals in an electron micrograph is not necessarily indicative of true crystalline nature. 
332 of annelid biomineralisation. It has a number of interesting features, such as a mixture of

333 calcite and aragonite polymorphs and a major developmental change in their proportions.

334 Although we found evidence of crystalline material from the earliest stages of plate

335 development, further research with more sensitive techniques is needed to clarify whether

336 an amorphous precursor phase is present at levels too low to be detected by our methods.

337 It will also be interesting to elucidate the relationship between calcium carbonate

338 polymorphs and the diverse structures observed throughout plate development, and

339 determine how polymorph selection is regulated at the ultrastructural and molecular levels.

340 The S. lamarcki operculum has great potential to contribute to our understanding of

341 biomineralisation in calcifying annelids. 
344 The authors would like to thank the members of the Ferrier and Somorjai labs for 345 discussions. RS was supported by a Carnegie Scholarship.

346

347

348 
Addadi L, Raz S, Weiner S (2003) Taking advantage of disorder: amorphous calcium carbonate and its roles in biomineralization. Adv Mater 15:959-970. doi: 10.1002/adma.200300381

Addadi L, Joester D, Nudelman F, Weiner S (2006) Mollusk shell formation: a source of new

Aizenberg J, Addadi L, Weiner S, Lambert G (1996) Stabilization of amorphous calcium carbonate by specialized macromolecules in biological and synthetic precipitates. Adv Mater 8:222-226. doi: 10.1002/adma.19960080307

Beniash E, Aizenberg J, Addadi L, Weiner S (1997) Amorphous calcium carbonate transforms into calcite during sea urchin larval spicule growth. Proc R Soc B 264:461 -465. doi: 10.1098/rspb.1997.0066

Beniash E, Metzler RA, Lam RSK, Gilbert PUPA (2009) Transient amorphous calcium phosphate in forming enamel. J Struct Biol 166:133-143. doi: 10.1016/j.jsb.2009.02.001

Bosence DWJ (1973) Recent serpulid reefs, Connemara, Eire. Nature 242:40-41. doi: $10.1038 / 242040$ b0

Bubel A (1983) A fine structural study of the calcareous opercular plate and associated cells a polychaete annelid. Tissue and Cell 15:457-476. doi: 10.1016/0040-8166(83)90076-9 
Bubel A, Thorp CH, Moore MN (1980) An histological, histochemical and ultrastructural study of the operculum of the serpulid Pomatoceros triqueter L. with particular reference to the formation of the calcareous opercular plate during opercular regeneration. In: Oxley TA, Becker G, Allsopp D (eds) Biodeterioration: The Proceedings of the Fourth International Biodeterioration Symposium. Biodeterioration Society, London, pp 275-290

Bubel A, Stephens RM, Fenn RH, Fieth P (1983) An electron microscope, X-ray diffraction and amino acid analysis study of the opercular filament cuticle, calcareous opercular plate and habitation tube of Pomatoceros lamarckii Quatrefages (Polychaeta: Serpulidae). Comp Biochem Physiol B 74:837-850. doi: 10.1016/0305-0491(83)90155-4

Bubel A, Thorp CH, Fenn RH, Livingstone D (1985) Opercular regeneration in Pomatoceros lamarckii Quatrefages (Polychaeta: Serpulidae). Differentiation of the operculum and deposition of the calcareous opercular plate. J Zool 1:49-94. doi: 10.1111/j.14697998.1985.tb00068.x

Cameron CB, Bishop CD (2012) Biomineral ultrastructure, elemental constitution and genomic analysis of biomineralization-related proteins in hemichordates. Proc R Soc B 279:3041-3048. doi: 10.1098/rspb.2012.0335

Cartwright JHE, Checa AG, Gale JD, et al. (2012) Calcium carbonate polyamorphism and its role in biomineralization: how many amorphous calcium carbonates are there? Angew Chem Int Ed 51:11960-11970. doi: 10.1002/anie.201203125

Chan VBS, Thiyagarajan V, Lu XW, et al. (2013) Temperature dependent effects of elevated $\mathrm{CO}_{2}$ on shell composition and mechanical properties of Hydroides elegans: insights 
from a multiple stressor experiment. PLoS ONE 8:e78945. doi: 10.1371/journal.pone.0078945

Chave KE (1952) A solid solution between calcite and dolomite. J Geol 60:190-192. doi: $10.1086 / 625949$

Cheng C, Shao Z, Vollrath F (2008) Silk fibroin-regulated crystallization of calcium carbonate. Adv Funct Mater 18:2172-2179. doi: 10.1002/adfm.200701130

397

Fornós JJ, Forteza V, Martínez-Taberner A (1997) Modern polychaete reefs in Western Mediterranean lagoons: Ficopomatus enigmaticus (Fauvel) in the Albufera of Menorca, Balearic Islands. Palaeogeography, Palaeoclimatology, Palaeoecology 128:175-186. doi:

Hedley RH (1958) Tube formation by Pomatoceros triqueter (Polychaeta). J Mar Biol Assoc UK 37:315-322. doi: 10.1017/S0025315400023717

Huang Y-C, Mou Y, Tsai TW-T, et al. (2012) Calcium-43 NMR studies of polymorphic transition of calcite to aragonite. J Phys Chem B 116:14295-14301. doi:

Kirschvink JL, Lowenstam HA (1979) Mineralization and magnetization of chiton teeth: paleomagnetic, sedimentologic, and biologic implications of organic magnetite. Earth 356. doi: $10.2113 / 0540329$ 
Lowenstam HA, Weiner S (1989) On biomineralization. Oxford University Press, New York

Marin F, Luquet G, Marie B, Medakovic D (2007) Molluscan shell proteins: primary structure, origin, and evolution. In: Gerald P. Schatten (ed) Current topics in developmental biology vol. 80. Academic Press, pp 209-276

Marin F, Le Roy N, Marie B (2012) The formation and mineralization of mollusk shell. Front Biosci (Schol Ed) 4:1099-1125. doi: 10.2741/S321

Medaković D, Popović S, Gržeta B, et al. (1997) X-ray diffraction study of calcification processes in embryos and larvae of the brooding oyster Ostrea edulis. Mar Biol

Ries JB (2011) Skeletal mineralogy in a high- $\mathrm{CO}_{2}$ world. J Exp Mar Biol Ecol 403:54-64. doi:

Ries JB, Cohen AL, McCorkle DC (2009) Marine calcifiers exhibit mixed responses to $\mathrm{CO}_{2^{-}}$ 10.1016/j.jembe.2011.04.006 induced ocean acidification. Geology 37:1131 -1134. doi: 10.1130/G30210A.1

Smith AM, McGourty CR, Kregting L, Elliot A (2005) Subtidal Galeolaria hystrix (Polychaeta: Serpulidae) reefs in Paterson Inlet, Stewart Island, New Zealand. NZ J Mar Freshw Res 39:1297-1304. doi: 10.1080/00288330.2005.9517394 
432

Smith AM, Riedi MA, Winter DJ (2013) Temperate reefs in a changing ocean: skeletal carbonate mineralogy of serpulids. Mar Biol 160:2281-2294. doi: 10.1007/s00227-0132210-z

Szabó R, Ferrier DEK (2014) Cell proliferation dynamics in regeneration of the operculum head appendage in the annelid Pomatoceros lamarckii. J Exp Zool (Mol Dev Evol) 322B:257268. doi: 10.1002/jez.b.22572

Tanur AE, Gunari N, Sullan RMA, et al. (2010) Insights into the composition, morphology, and formation of the calcareous shell of the serpulid Hydroides dianthus. J Struct Biol 169:145-160. doi: 10.1016/j.jsb.2009.09.008

Taylor PD, Kudryavtsev AB, Schopf JW (2008) Calcite and aragonite distributions in the skeletons of bimineralic bryozoans as revealed by Raman spectroscopy. Invert Biol 127:87-97. doi: 10.1111/j.1744-7410.2007.00106.x

Thomas JG (1940) Pomatoceros, Sabella and Amphitrite. University Press of Liverpool, Liverpool

Vinn O (2013) On the unique isotropic aragonitic tube microstructure of some serpulids (Polychaeta, Annelida). J Morphol 274:478-482. doi: 10.1002/jmor.20112

Vinn O, ten Hove HA (2011) Microstructure and formation of the calcareous operculum in Pyrgopolon ctenactis and Spirobranchus giganteus (Annelida, Serpulidae). Zoomorphology 130:181-188. doi: 10.1007/s00435-011-0133-0 
451 Vinn O, Jäger M, Kirsimäe K (2008a) Microscopic evidence of serpulid affinities of the problematic fossil tube "Serpula" etalensis from the Lower Jurassic of Germany. Lethaia 41:417-421. doi: 10.1111/j.1502-3931.2008.00093.x

Vinn O, ten Hove HA, Mutvei H, KirsimäE K (2008b) Ultrastructure and mineral composition of serpulid tubes (Polychaeta, Annelida). Zool J Linn Soc 154:633-650. doi: 10.1111/j.1096-3642.2008.00421.x

Vinn O, Mutvei H, ten Hove HA, Kirsimäe K (2008c) Unique Mg-calcite skeletal ultrastructure 458 in the tube of the serpulid polychaete Ditrupa. Neues Jahrbuch für Geologie und Paläontologie - Abhandlungen 248:79-89. doi: 10.1127/0077-7749/2008/0248-0079 (Polychaeta, Serpulidae): Implications for the tube formation of serpulids. Estonian J Earth Sci 58:148-152.

Weiss IM, Tuross N, Addadi L, Weiner S (2002) Mollusc larval shell formation: amorphous calcium carbonate is a precursor phase for aragonite. J Exp Zool 293:478-491. doi: 10.1002/jez.90004 

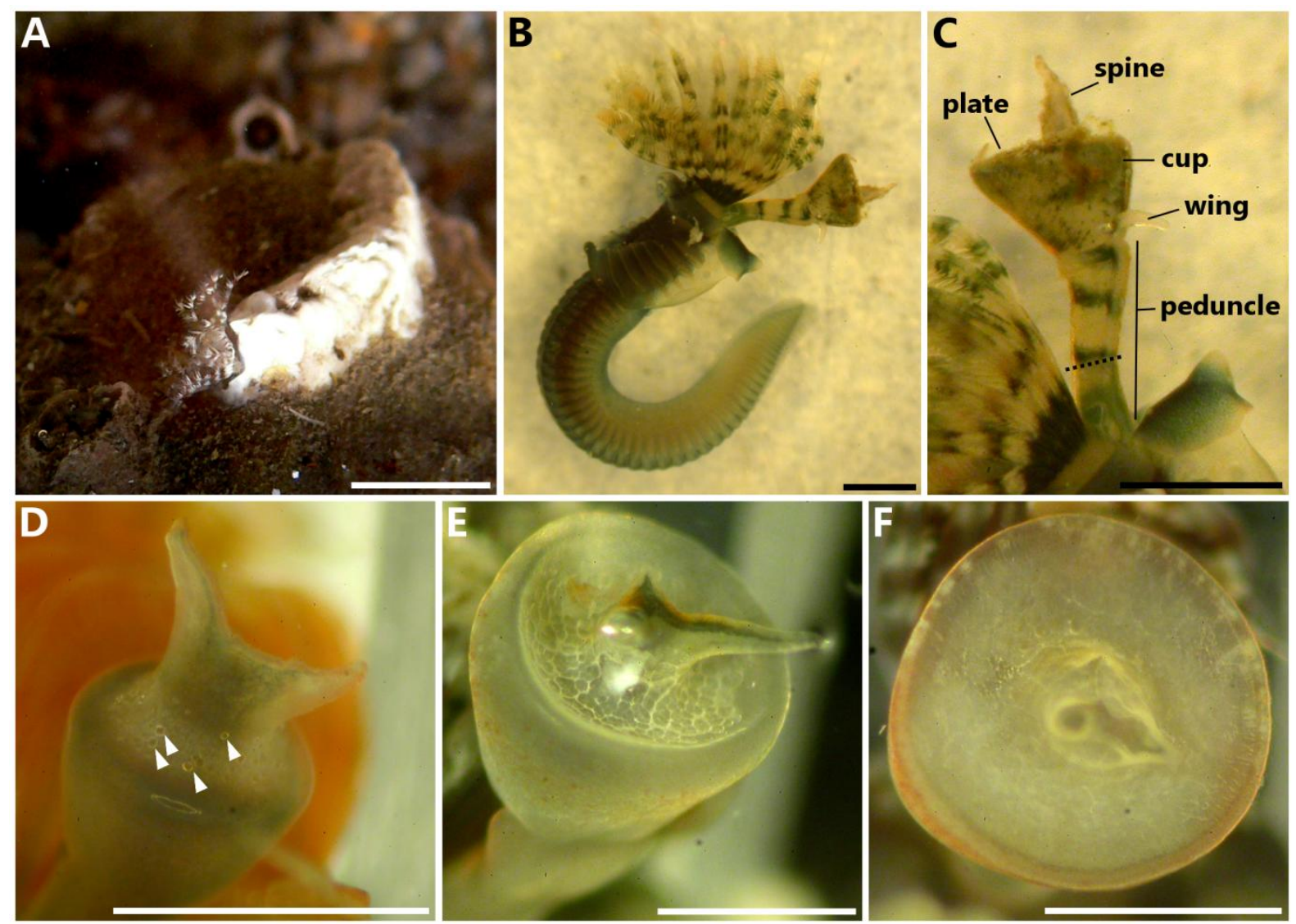

Fig. 1

Spirobranchus lamarcki and the calcified opercular plate. A. Spirobranchus sp. in its natural habitat. White and dark banded tentacles extended; rest of worm hidden in calcareous tube. Photographed in an intertidal rock pool at Castle Sands, St Andrews, Scotland. Scale $5 \mathrm{~mm}$. B. Adult S. lamarcki removed from tube. Left lateral view, anterior towards the top. C. Close-up of mature opercular filament from B. Major anatomical structures labelled. Dotted line marks easy break point (autotomy plane and experimental amputation site). Scale bars in B-C $1 \mathrm{~mm}$. D-F development of the calcified plate during regeneration. D. Early calcification in a regenerating operculum $3 \mathrm{~d}$ post-operation (dpo). Whitish band around base of spine is composed of small crystalline grains (see Fig. 2 for details). Arrowheads mark "tiles". E. 6 dpo operculum with plate showing pronounced tiling. F. 18 dpo opercular plate with a nearly smooth appearance. Scale bars in $\mathbf{D}-\mathbf{F} \sim 0.5 \mathrm{~mm}$ 

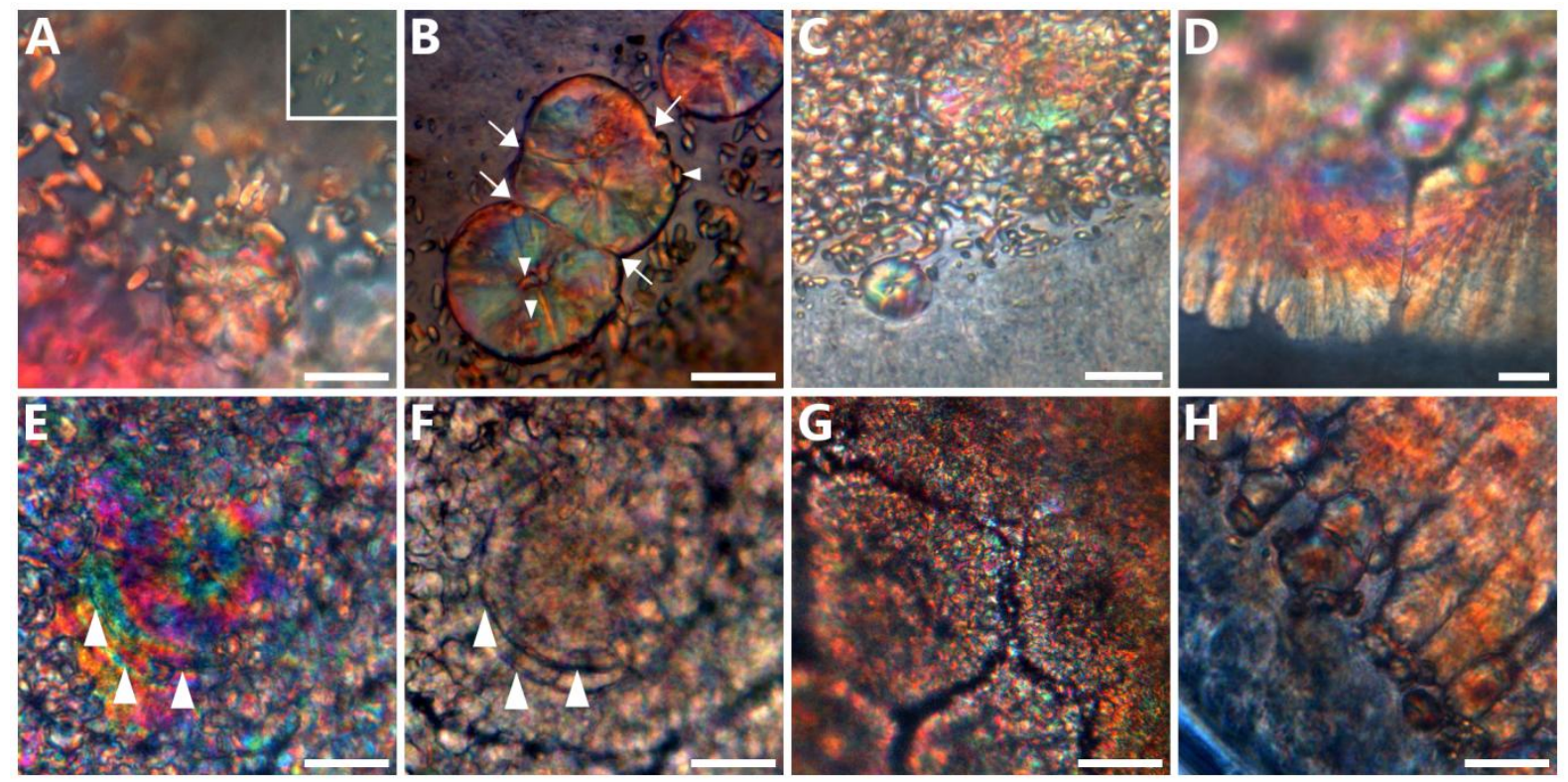

Fig. 2

Features of plate calcification. Details of fresh opercular plates imaged with differential interference contrast (DIC) optics unless otherwise indicated. Scale bars are $20 \mu \mathrm{m}$. A. Grains and small tile from base of spine on a 2 dpo specimen. Reddish background is from opercular blood vessel. Inset (same scale) shows smaller grains at edge of calcifying area from same operculum. B. Extended depth of field (EDF) image of three merging tiles from a 3 dpo specimen. Arrows indicate sites of contact. Arrowheads indicate grains associated with tiles. C. Edge of the calcified plate of a 4 dpo specimen. D. Edge of 10 dpo plate showing large fan-shaped structures. E. Large tile displaying growth rings (arrowheads) in central region of a 10 dpo plate. F. Brightfield image of the tile in $\mathbf{E}$ with growth lines indicated. G. Central area of 14 dpo plate. H. Edge of plate in specimen from G. 

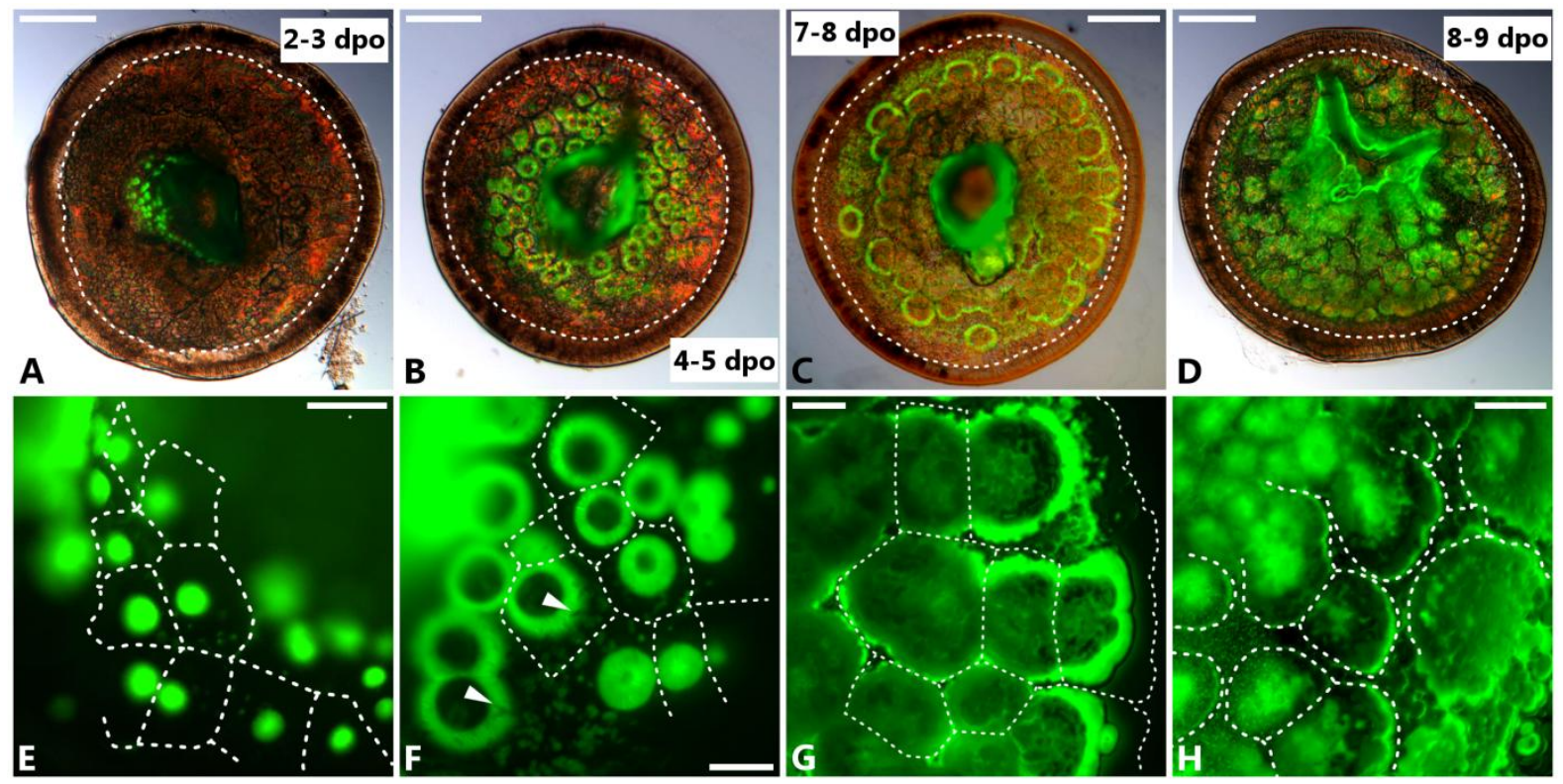

Fig.3

Calcein-labelled opercular plates. A-D Overview of calcein staining. Panels are composites of calcein (green) and DIC images of opercular plates taken with EDF. All pictured specimens fixed at $14 \mathrm{dpo}$; pulse time is indicated in each panel. Dashed white lines indicate approximate outline of total calcified area. Scale bars $250 \mu \mathrm{m}$. A. 2-3 dpo pulse. B. 4-5 dpo pulse. C. 7-8 dpo pulse. D. 8-9 dpo pulse. E-H Details of calcein staining. Scale bars $50 \mu \mathrm{m}$. E-F are single-focus images, $\mathbf{G - H}$ are EDF image stacks. Dashed lines are tile outlines visible in corresponding DIC image (E-H) and edge of calcified area (G). E. Spine base of 2-3 dpo specimen. F. 4-5 dpo pulse (same specimen as B). Arrowheads show unstained grains obscuring ring-like staining in tiles. Bright area to top left is the spine. G. 7-8 dpo pulse (same specimen as C). H. 9-10 dpo pulse. Centre of plate is towards top left. 
A

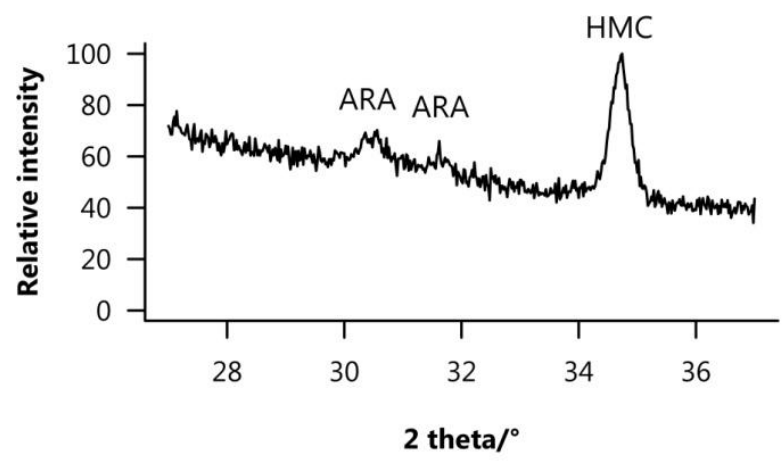

B

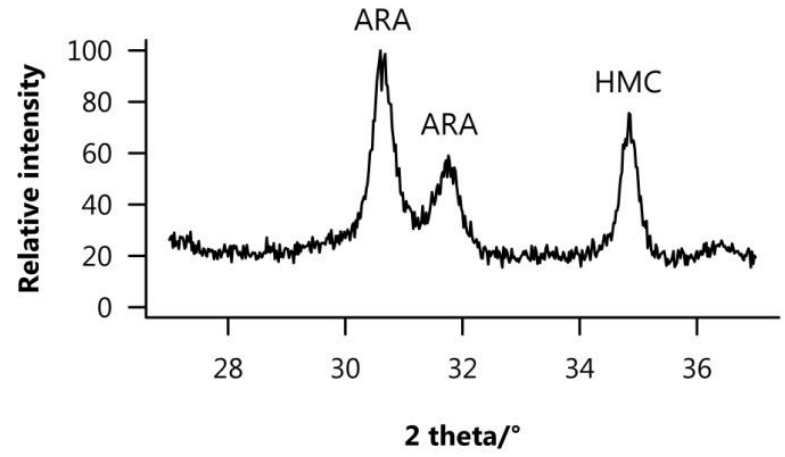

C

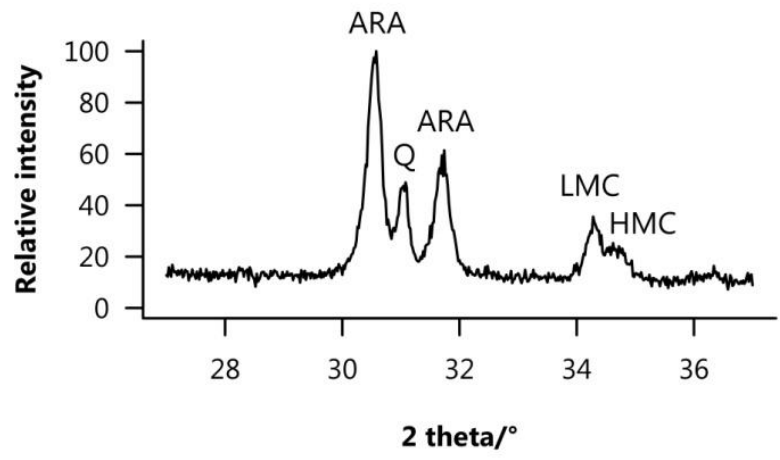

D

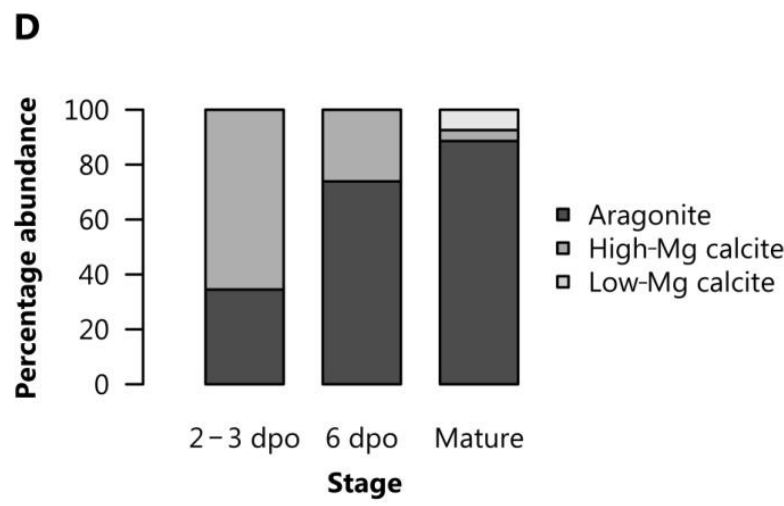

Fig. 4

Development of opercular plate mineralogy. A-C X-ray

diffractograms of plate mineral extracted from two regeneration stages and non-regenerating opercula. Intensities scaled to the highest peak in each sample (not to scale between samples). ARA = aragonite, $\mathrm{LMC}=$ low-Mg calcite, $\mathrm{HMC}=$ high-Mg calcite $12-16 \%$ w/w $\mathrm{MgCO}_{3}$ ). A. Early calcifying (2-3 dpo) opercula $(n=220)$. B. 6 dpo specimens $(n=98)$. C. Mature opercula $(n=79)$. Quartz peak (Q) probably due to environmental sand contamination. D. Percentage composition of opercular plate mineral estimated from data in A-C. 